GUT MOTILITY

\title{
Inhibitory actions of a high fibre diet on intestinal gas transit in healthy volunteers
}

\author{
S Gonlachanvit, R Coleski, C Owyang, WL Hasler
}

Gut 2004;53:1577-1582. doi: 10.1136/gut.2004.041632

See end of article for authors' affiliations

.....................

Correspondence to: Dr W L Hasler, 3912 Taubman Center, Box 0362, Ann Arbor, MI 48109, USA; whasler@ umich.edu

Revised version received 7 April 2004

Accepted for publication

13 April 2004 Background: Fibre treatment often produces gaseous symptoms which have been attributed to
fermentation by colonic bacteria with increased gas production. Effects of fibre ingestion on intestinal gas flow are unexplored.

Aims: We aimed to test the hypothesis that consumption of a high fibre diet retards gas transit.

Subjects: Ten healthy volunteers participated.

Methods: To investigate the effects of fibre on gas dynamics, physiological gas mixtures were jejunally perfused at $12 \mathrm{ml} / \mathrm{min} \times 2$ hours after a standard diet for seven days with and without psyllium $30 \mathrm{~g} /$ day in a crossover fashion. Gas was collected from an intrarectal catheter to bypass the anus and evacuation was quantified in real time using a barostat.

Results: On initiating gas perfusion under control conditions, an initial lag phase with no gas expulsion was observed (1129 (274) seconds). Thereafter, gas evacuation from the rectum proceeded with cumulative volumes of $1429(108) \mathrm{ml}$ by the end of the second hour. Evacuation was pulsatile with passage of 20.9 (2.5) boluses, with mean volumes of 68.2 (5.0) ml. Fibre prolonged the lag time (2265 (304) seconds; $p<0.05$ ) and reduced cumulative gas evacuation volumes (1022 (80) $\mathrm{ml} ; \mathrm{p}<0.05)$. Decreased gas evacuation resulted from reductions in the numbers of bolus passages $(14.2(1.1) ; p<0.05)$ but not bolus volumes (70.7 (3.4) ml; $\mathrm{p}=0.66$ ).

Conclusions: Consumption of a high fibre diet retards intestinal gas transit by decreasing bolus propulsion to the rectum. Thus, in addition to increasing gas production by colonic flora, fibre ingestion may elicit gaseous symptoms by promoting gas retention. latis ncreased fibre consumption is advocated for patients with constipation. ${ }^{1}$ Fibre has other beneficial effects, including reducing serum cholesterol, preventing colon cancer, decreasing faecal incontinence, relieving symptoms from diverticulosis, and improving glycaemic control in diabetics. ${ }^{2-5}$ From these observations, it has been recommended that daily fibre intake should range between 20 and 35 g. ${ }^{6}$ However, $15-20 \%$ of those prescribed high fibre diets experience pronounced gaseous symptoms, including bloating and uncomfortable abdominal distension.

Symptoms from fibre supplemented diets can be attributed to fermentation of the fibre by colonic bacteria with increased gas production. Different fibre preparations have varied effects on gas generation. ${ }^{78}$ Psyllium is a partially fermented fibre commonly used in irritable bowel syndrome (IBS) which increases stool weight and promotes laxation. However, psyllium and other sources, including bran, corn bran, and cellulose, produce relatively little increase in flatus production suggesting that gas related symptoms after fibre result from mechanisms other than bacterial fermentation. ${ }^{8} 9$ Increasing dietary fibre has modulatory effects on motor function, including retarding gastric emptying and accelerating colonic transit. ${ }^{10-12}$ The effects of fibre on transit of gas within the gastrointestinal tract have not been explored.

In this study, we used a validated technique of jejunal gas perfusion to test the hypothesis that fibre supplementation with psyllium retards gas transit and promotes gas retention. ${ }^{13}$ Healthy humans underwent placement of perfusion catheters beyond the ligament of Treitz and collection catheters in the rectum. Perfusion of a physiological gas mixture was performed after seven days of a standard diet and after seven days of a standard diet supplemented with psyllium in random order in a crossover fashion. Volumes, flow rates, and pressures of rectal gas evacuations were compared on the diets. Throughout these investigations, we hoped to characterise the effects of fibre on gas transit and to gain insight into gaseous symptoms associated with fibre supplementation.

\section{MATERIALS AND METHODS Test subjects}

Ten healthy volunteers (eight males, two females; aged 1946 years) with no history of gastrointestinal symptoms, no prior gastrointestinal surgery, and on no medications known to alter gut motor function or transit were recruited through campus wide advertisement. Each subject gave written informed consent before entering the study. Women of child bearing potential underwent serum pregnancy testing prior to enrolment. All studies were approved by the University of Michigan Medical Center Institutional Review Board.

\section{Study design}

All subjects underwent two gas dynamic studies, each after a seven day period on a standard diet (subjects' usual diets) or a standard diet supplemented with psyllium $10 \mathrm{~g}$ three times daily with each meal (total daily psyllium intake $30 \mathrm{~g}$ ) in a crossover fashion at least seven days apart in random order. Volunteers fasted overnight and reported at 7:30am on each study day. Subjects underwent initial rectal evacuation with a $500 \mathrm{ml}$ water enema. A silicone rubber catheter with an outside diameter of $4.2 \mathrm{~mm}$ and a $1.9 \times 2.4 \mathrm{~mm}$ central lumen open at its tip (Dentsleeve Pty Ltd, Wayville, SA, Australia) was passed using fluoroscopy with positioning of the tip $5 \mathrm{~cm}$ distal to the ligament of Treitz for gas perfusion. A $24 \mathrm{Fr}$ Foley catheter was inserted into the rectum for gas collection. The subject was placed in a quiet room and lay supine at a $30^{\circ}$

Abbreviations: IBS, irritable bowel syndrome 
incline for a 30 minute equilibration period prior to initiation of gas perfusion.

\section{Jejunal gas perfusion}

A gas mixture containing 88\% nitrogen, $6.5 \%$ carbon dioxide, and $5.5 \%$ oxygen was perfused into the jejunum at a rate of $12 \mathrm{ml} / \mathrm{min}$. The technique has been previously validated. ${ }^{13}$ This mixture of gases approximates concentrations in venous blood and thus has been termed physiological. Furthermore, there is no significant gas reflux into the stomach and $95 \%$ of perfused gas is recovered in the rectum. Gas perfusion was controlled by a digital mass flow controller (Brooks Smart Mass Flow Controller, Model 5850S; Brooks Instrument, Hatfield, Pennsylvania, USA) which served to pump the gas mixture into the jejunum at the predetermined fixed rate of $12 \mathrm{ml} / \mathrm{min}$. Flow entering the jejunum was monitored by a digital mass flowmeter (Brooks Smart Flow Meter, Model 5860E; Brooks Instruments) which continuously measured the rate of gas perfusion into the jejunum and served as a control to confirm that the desired flow rate was maintained at $12 \mathrm{ml} / \mathrm{min}$ at all times. The mass flow controller and the mass flowmeter were interfaced with a personal computer (Dimension 8200; Dell Inc., Round Rock, Texas, USA) via a digital converter (USB Data Acquisition Function Module; Data Translation Inc., Marlboro, Massachusetts, USA). Rates of gas perfusion were set and monitored using Data Acquisition Software version 1.0 (Data Translation Inc.).

\section{Quantification of evacuated gas}

Evacuated gas collected from the rectal catheter was connected to low resistance, low compliance tubing and was measured by a barostat (Isobar III; G\&J Electronics, Hamilton, Ontario, Canada) which was controlled by Protocol Plus Software (G\&J Electronics). Prior to the study, the barostat was emptied and the pressure was set at
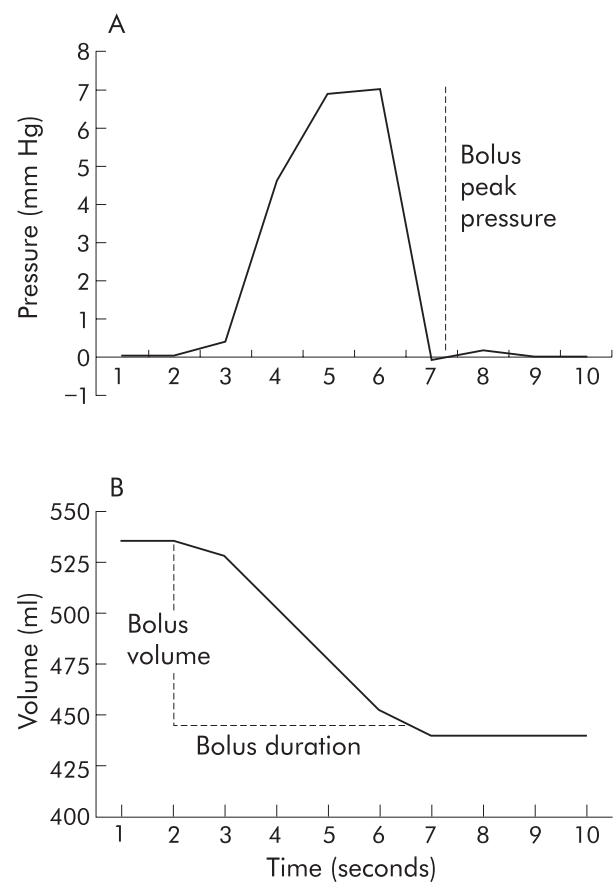

Figure 1 Sample pressure (A) and volume (B) tracings from the barostat are shown during a bolus gas evacuation from the rectum. (A) Peak bolus pressure is defined as the pressure difference between maximal pressure and baseline pressure. (B) Bolus volume and duration are displayed. Bolus volume is the volume difference between the volume before and after gas evacuation. Bolus duration is the time needed for $90 \%$ of the bolus volume to be evacuated.
$0 \mathrm{~mm} \mathrm{Hg}$ with a sensitivity of $0.3 \mathrm{~mm} \mathrm{Hg}$ and a maximum flow rate of $35 \mathrm{ml} / \mathrm{s}$. Any gas flow generating a pressure $>0.3 \mathrm{~mm} \mathrm{Hg}$ was collected into the barostat. Volumes and pressures of gas collected in the barostat were recorded at a sampling frequency of $\mathrm{l} \mathrm{Hz}$ over the two hour perfusion period for subsequent analysis.

\section{Intestinal gas dynamic parameters}

After an initial lag period, gas was evacuated from the rectum either as bolus movements or as continuous flow during jejunal gas perfusion. The lag period was defined as the time from initiation of gas perfusion to the first passage of $>20 \mathrm{ml}$ of gas from the rectum. Bolus movements were defined as passages $>10 \mathrm{ml}$ in volume at a rate $>2 \mathrm{ml} / \mathrm{s}$ with an interval between movements $>10$ seconds, regardless of the pressure of the gas movement. Volume, duration, and peak pressure for each bolus movement were determined as shown in fig 1 . The flow rate for each bolus movement was calculated by dividing the bolus volume by its duration. Continuous flow was defined as any volume of gas evacuated in a given time that did not exhibit a discrete passage of $10 \mathrm{ml}$ and that occurred at a rate $<2 \mathrm{ml} / \mathrm{s}$. Inspection of evacuation profiles during periods of continuous flow revealed slow linear gas volume expulsions lasting 1-3 minutes without abrupt changes in volume or pressure. These slow linear gas expulsions were not secondary to leaks in the system as continuous flow rates varied during individual recording sessions and included recording segments in which no gas was evacuated. The total gas volume evacuated during jejunal perfusion was calculated as the sum of bolus and continuous gas flow volumes.
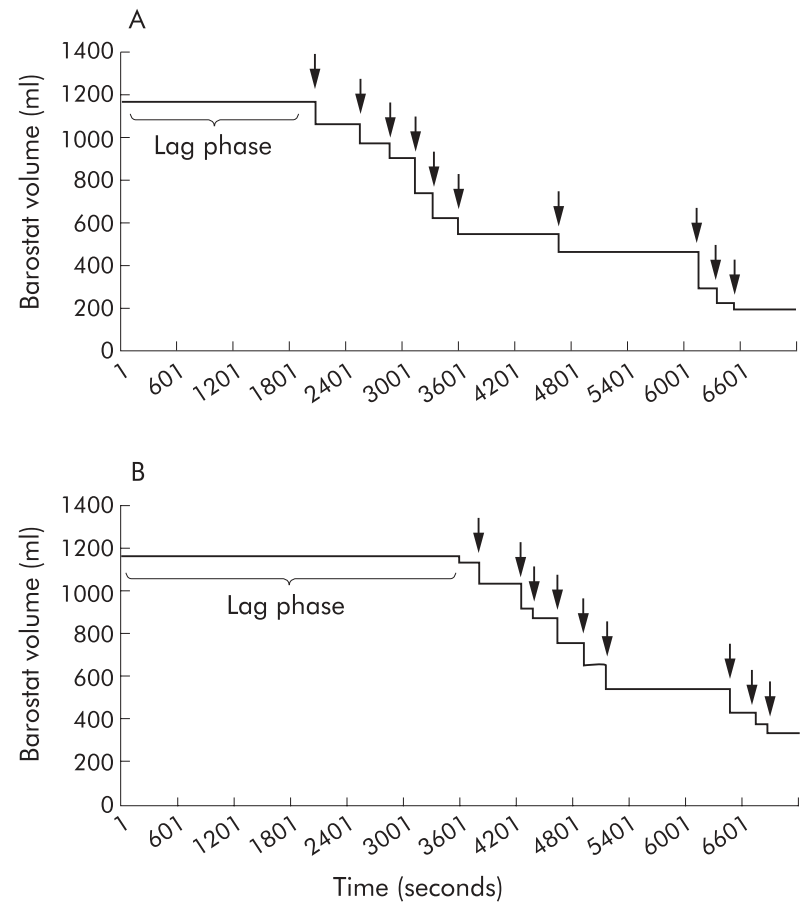

Figure 2 Sample gas evacuation profiles are shown for a healthy individual after seven days on a standard $\operatorname{diet}(\mathrm{A})$ and seven days on a standard diet supplemented with psyllium (B). In each case, gas evacuation is pulsatile with passage of discrete boluses (arrows) after a lag period after initiation of jejunal gas perfusion during which time no gas expulsion occurs. The tracing on the high fibre diet is characterised by passage of fewer gas boluses after a more prolonged lag phase than on the standard diet. 


\section{Statistical analysis}

All results are expressed as mean (SEM). Intestinal gas dynamic parameters, including lag times to first evacuation, bolus volume, bolus pressure, bolus flow rate, and continuous flow rate were compared using two tailed Student's paired $t$ testing on the standard diet and the standard diet supplemented with psyllium. Repeated measures ANOVA was employed to compare gas retention and bolus evacuation numbers as a function of time on the two diets. A p value $<0.05$ defined statistical significance.

\section{RESULTS}

All volunteers completed both perfusion studies after ingestion of a standard diet and a standard diet supplemented with $30 \mathrm{~g}$ of psyllium for seven days. Representative gas evacuation profiles for one volunteer on each diet are shown in fig 2. On a standard diet, evacuation was predominantly pulsatile in nature and proceeded after a lag period in which no expulsion occurred. With ingestion of the fibre supplemented diet, evacuations also occurred in bolus fashion which occurred after a more prolonged lag phase of no expulsion.

\section{Comparison of diet effects on gas evacuation}

The fibre supplemented diet had pronounced effects on several parameters related to gas expulsion and retention. The lag time from initiation of perfusion to the first rectal gas expulsion was prolonged on the high fibre diet compared with the standard diet $(p<0.05)$ (fig 3$)$. Nine of 10 volunteers exhibited a longer lag phase on the diet supplemented with psyllium. Conversely, there was a significant decrease in the total gas evacuated on the fibre supplemented diet versus the standard diet $(\mathrm{p}<0.05)$ (fig 4$)$. Gas retention was calculated by subtracting cumulative gas expelled from the rectum from cumulative gas perfused in the jejunum. Because of the longer lag phase, gas retention was significantly greater on the high fibre diet compared with the standard diet during the initial perfusion period and reached a maximum 50 minutes after starting gas perfusion $(p<0.05)$ (fig 5$)$. During the second hour of gas perfusion, gas retention profiles on the standard diet and diet supplemented with psyllium did not converge. Gas retention remained more pronounced on the fibre supplemented diet than on the standard diet throughout the remainder of the gas perfusion period $(\mathrm{p}<0.05)$ (fig 5$)$.

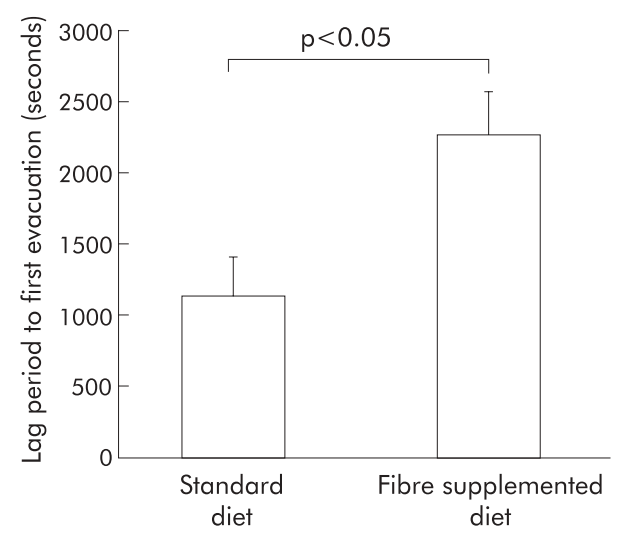

Figure 3 Lag time from initiation of jejunal gas perfusion to the first bolus gas passage is shown for the standard diet and the fibre supplemented diet. Consumption of the diet supplemented with psyllium significantly prolonged the lag phase $(p<0.05)$. Results are mean (SEM), $n=10$.

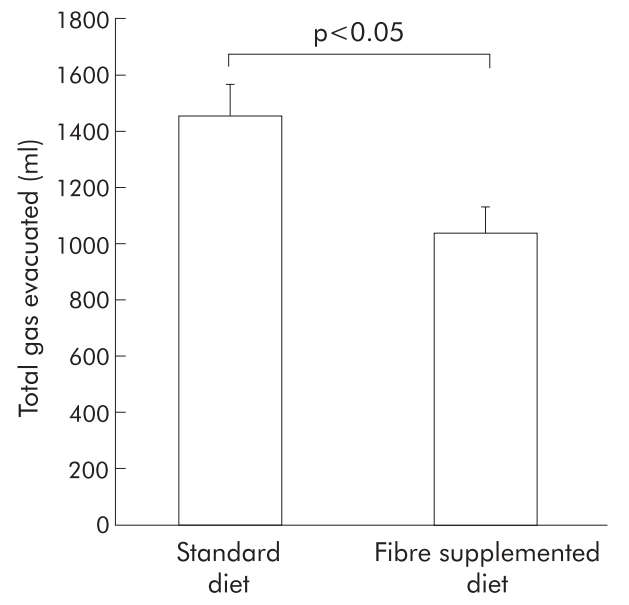

Figure 4 Total gas evacuated during the two hour jejunal gas perfusion period is shown for the standard diet and the diet supplemented with psyllium. Gas expelled after consumption of the high fibre diet was significantly less than that occurring after ingestion of the standard diet $(p<0.05)$. Results are mean (SEM), $n=10$.

\section{Characterisation of gas evacuation profiles}

Effects of fibre on cumulative gas flow resulted primarily from effects on bolus evacuations from the rectum. Only small amounts of gas were expelled in a continuous fashion, not as part of a bolus. Continuous expulsion was not different on a standard diet $(0.6(0.3) \%)$ and a diet supplemented with psyllium $(1.8(0.6) \%)(p=0.17)$. Total numbers of evacuations were lower on a fibre supplemented diet versus the standard diet $(\mathrm{p}<0.05)$ (fig $6 \mathrm{~A})$. To subtract the effects of the lag phase, numbers of boluses per 30 minutes after completion of the lag phase were calculated. After excluding the lag phase, rates of bolus expulsion were decreased on the high fibre diet compared with the standard diet $(\mathrm{p}<0.05)$ (fig 6B). Furthermore, bolus expulsion rates as a function of time demonstrated greater numbers of evacuations in each

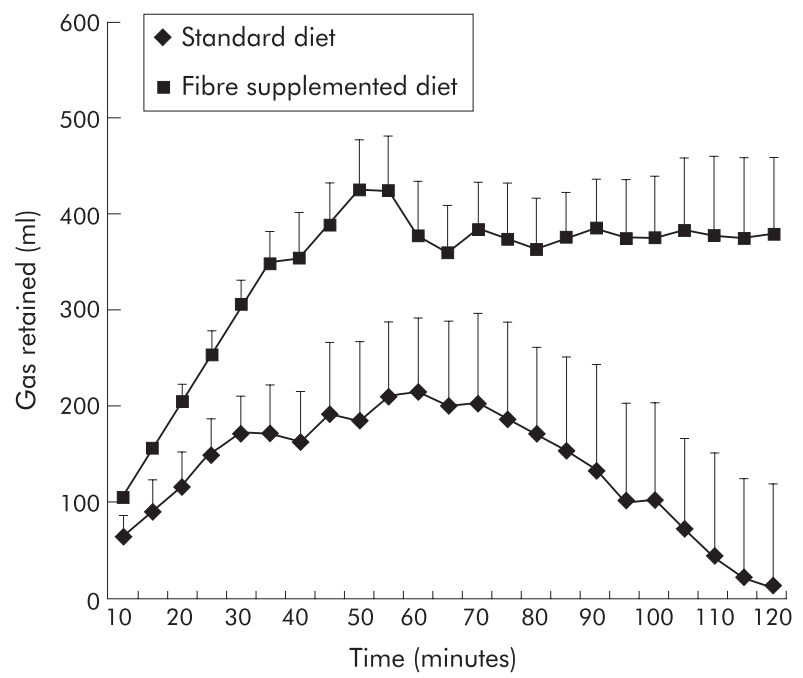

Figure 5 Gas retention is plotted as a function of time after initiation of iejunal gas retention for the standard diet and the fibre supplemented diet. Gas retention was maximal 50 minutes after initiation of gas perfusion on the high fibre diet and was significantly greater than that observed on the standard diet ( $p<0.05$ by ANOVA). After this time, the gas retention profiles on the two diets did not converge. Gas retention remained prolonged throughout the remainder of the gas perfusion period and was still prolonged on the fibre supplemented diet at 120 minutes ( $p<0.05$ by ANOVA). Results are mean (SEM), $n=10$. 

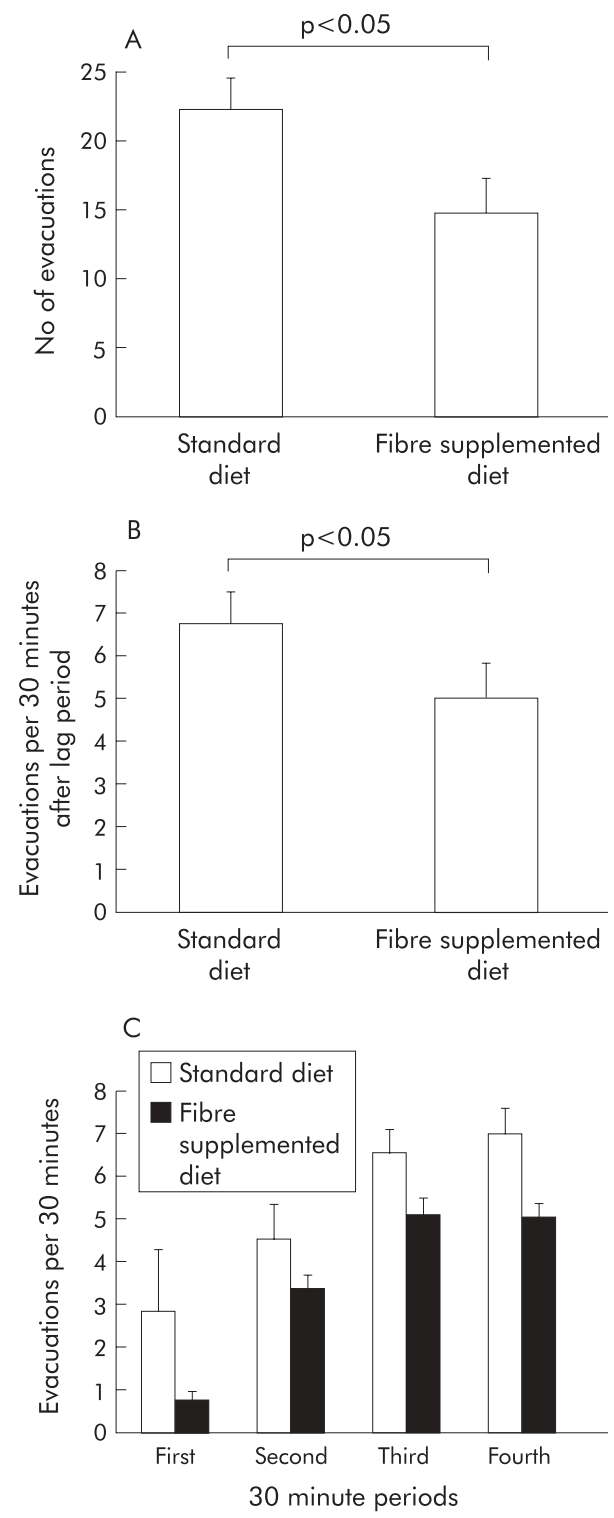

Figure 6 Numbers of gas evacuations during the two hours of the study (A) and calculated per 30 minutes of recording time after excluding the lag period (B) are shown for the standard diet and the diet supplemented with psyllium. (A) Total numbers of gas evacuations were significantly less on the high fibre diet compared with the standard diet $(p<0.05)$. (B) After exclusion of the lag phase, numbers of bolus evacuations per 30 minutes remained reduced on the fibre supplemented diet compared with the standard diet $(p<0.05)$. (C) Finally, when comparing bolus evacuations during each 30 minute recording period, evacuation numbers were greater on the standard diet compared with the high fibre $\operatorname{diet}(p<0.05$ by ANOVA). Results are mean (SEM), $n=10$.

30 minute time period of gas perfusion on the standard diet versus the fibre supplemented diet $(p<0.05)$ (fig 6C). Rates of gas flow during each bolus and bolus durations were unaffected by fibre $(\mathrm{p}=0.27$ and $\mathrm{p}=0.66$, respectively) (table 1). Similarly, volumes and pressures of each bolus were similar on the fibre supplemented and standard diets ( $p=0.66$ and $p=0.72$, respectively) (table 1$)$.

\section{DISCUSSION}

Beneficial effects of fibre include relieving constipation in IBS, reducing serum cholesterol, decreasing the risk of colonic neoplasia, and improving glycaemic control in diabetes. ${ }^{1-5}$ Bloating, flatulence, and eructation are prominent complaints of many IBS patients. ${ }^{14}$ Studies have shown that fibre exacerbates rather than relieves gaseous complaints in IBS. In an uncontrolled investigation, bran worsened symptoms in $55 \%$ of patients but provided benefits in only $10 \%{ }^{15}$ Other controlled trials of bran have reported increases in bloating and gas in IBS compared with placebo. ${ }^{16}$

It is not known why fibre increases gaseous complaints. Studies have shown correlations between fibre intake and daily flatus emissions. ${ }^{17}{ }^{18}$ Most fibre compounds are comprised of complex carbohydrates. Complex carbohydrates in dietary wheat, oats, and potatoes increase production of hydrogen and other gases. ${ }^{19}$ Similarly, guar increases colonic methane production. ${ }^{20}$ Although they are partially fermented, psyllium and ispaghula husks do not promote gas generation by gut flora, indicating that mechanisms other than bacterial fermentation elicit gaseous symptoms during fibre therapy. ${ }^{20-23}$ Investigations of fibre effects on nongaseous luminal transit provide conflicting results. Bran accelerates colonic transit of stool whereas psyllium has variable effects on stool propulsion. ${ }^{11}{ }^{12} 2124-27$ Effects of fibre on small intestinal transit of meal residues are largely unexplored. One report noted more prolonged small bowel transit of bran than lactulose but this may have been secondary to the propulsive effects of lactulose rather than an inhibitory action of the fibre. ${ }^{928}$

The present investigation is the first rigorous analysis of the effects of fibre on transit of intestinal gas. In this study, psyllium retarded expulsion of jejunally perfused physiological gas mixtures. Most prominently, fibre prolonged the lag time from initiation of gas perfusion to the first gas expulsion and promoted gas retention which was most significant in the initial hour of the study. Moreover, after completion of the lag phase, gas expulsion proceeded at a reduced rate on a fibre supplemented diet compared with that observed on a standard diet. At the end of the study, gas retention was pronounced on the high fibre diet whereas little gas was retained on the standard diet. There were no differences in the properties of each individual bolus, including bolus volumes or pressures.

The mechanisms responsible for the delay in intestinal gas transit elicited by dietary fibre are unknown. It is possible that the increased bulk of the high fibre diet provides a mechanical impediment to aboral gas movement. Consumption of a diet with $30 \mathrm{~g}$ of psyllium produces an increase in stool weight of $226 \mathrm{~g} /$ day. ${ }^{24}$ Prolongation of the lag phase conceivably could be secondary to an increased volume of stool within the colonic lumen which precludes evacuation of the initial bolus until a sufficient pressure is built up proximally by the jejunally perfused gas mixture.

Table 1 Effects of fibre supplementation on properties of bolus gas evacuations

\begin{tabular}{lccl}
\hline Parameter & Standard diet & High fibre diet & p Value \\
\hline Bolus flow rate $(\mathrm{ml} / \mathrm{min})$ & $13.8(0.6)$ & $14.7(0.6)$ & 0.27 \\
Bolus duration $(\mathrm{s})$ & $5.4(0.4)$ & $5.2(0.4)$ & 0.66 \\
Bolus volume $(\mathrm{ml})$ & $68.2(6.0)$ & $70.7(4.2)$ & 0.66 \\
Bolus pressure $(\mathrm{mm} \mathrm{Hg})$ & $13.3(1.8)$ & $13.8(1.9)$ & 0.72 \\
\hline
\end{tabular}


Alterations in reflex responses of the colon to increased bulking by the fibre supplement also may modulate intestinal gas transit. Mucosal stimulation or muscle stretch by colonic contents evoke distinct orad and caudad motor responses which comprise the peristaltic reflex. ${ }^{29}$ It is conceivable that prolonged colonic distension with psyllium may inhibit contractile responses or elicit a prolonged relaxation phase. However, other investigators have shown that duodenal or rectal distension accelerates rather than retards gas transit during duodenal lipid perfusion. ${ }^{30}$ Given that this study was done with an acute distending stimulus with a concurrent retarding nutrient intervention, it is uncertain if this model is applicable to the findings of our study.

Alterations in gut motor function elicited by psyllium also may play important roles in the delayed transit of perfused gas after a high fibre diet. Our observation that the frequency of gas evacuations after completing the lag phase remained reduced on the psyllium supplemented diet is consistent with the postulate that contractile patterns responsible for gas transit are modified by dietary fibre. The finding that most gas is evacuated as discrete boluses suggests the involvement of phasic motor complexes in their expulsion. The lack of effect of fibre on flow rates, durations, volumes, or pressures of individual boluses is consistent with the explanation that psyllium modulates the frequency of occurrence of propulsive contractile waves rather than their intensity, propagation velocity, or other parameters. This hypothesis warrants further testing.

Available data suggest significant modification of colonic motility by the fibre content of the diet. In animal models, a low residue diet increases colonic motility indices whereas a high fibre content decreases intraluminal pressure and number of fasting and fed contractions. ${ }^{31}{ }^{32}$ In humans, bran decreases colonic contractile activity in patients with diverticular disease as well as individuals with IBS..$^{33}{ }^{34}$ Decreases in colonic motility index on a fibre supplemented diet have been attributed to reductions in non-propulsive contractile activity with preservation of propagative pressure waves, as short spike bursts but not caudally migrating long spike bursts are blunted by fibre intake. ${ }^{35}$ This effect has been postulated to result from binding of motor stimulatory bile acids in the colon by fibre. ${ }^{34}$ Conversely, other studies report increases in colonic contractions with fibre. ${ }^{25}{ }^{36}$ However, it is not clear how modifications in colonic motility could accelerate transit of solid faeces but promote luminal gas retention.

It is not known if the intestinal transit of gas generated by eating a standard diet mimics the movements of the jejunally perfused gas mixture employed in the present investigation. Thus it is uncertain if psyllium inhibits transit of endogenous gases. However, if retardation of the perfused gas in part results from the mechanical effects of the fibre supplement, it is likely that a similar mechanism is operant after ingestion of a diet rich in poorly digestible oligo- and polysaccharides. If psyllium bulking is prominent, it is possible that gases produced by fermentation of incompletely metabolised starches in the caecum and right colon by enteric bacteria might be retained until sufficient amounts are generated to push past the impediment. This issue is worthy of additional investigation.

Other issues regarding this investigation can be questioned. Only a single fibre source was employed in this study and thus it is not certain that other fibre supplements would have similar effects. It is conceivable that subjects taking psyllium supplements may have slightly decreased fibre content of their meals and thus the daily difference in fibre intake between the two diets may have been less than $30 \mathrm{~g}$. However, as most normal individuals typically consume much less than $30 \mathrm{~g} /$ day, it is likely the fibre intake was significantly greater on the psyllium supplemented diet.
Finally, it is possible that the retardation of gas flow by fibre supplementation might promote enhanced diffusion of the perfused gas into the bloodstream. This hypothesis cannot be tested using the current methodology. ${ }^{13}$ However, it is possible that utilisation of a washout method with an inert gas such as argon, as has been previously described, would provide quantification of volumes of gas retained within the gut on the two diets to answer this question. ${ }^{37}$ However, such a finding would not alter the main thrust of this investigation-that consumption of a high fibre diet modifies the dynamics of jejunally perfused gas mixtures.

In conclusion, consumption of a diet supplemented with psyllium retards transit of gas perfused into the jejunum in healthy humans by prolonging the lag time to first evacuation and decreasing the numbers of bolus passages from the rectum after completion of the lag phase. These observations provide a possible explanation for the increase in gaseous symptoms, including bloating, observed on a high fibre diet.

\section{ACKNOWLEDGEMENTS}

This research was sponsored in part by a grant 1 K24 DK02726-01 from the National Institutes of Health.

\section{Authors' affiliations}

S Gonlachanvit, R Coleski, C Owyang, W L Hasler, Division of Gastroenterology, Department of Internal Medicine, University of Michigan Medical Center, Ann Arbor, MI, USA

\section{REFERENCES}

1 Drossman DA, Camilleri M, Mayer EA, et al. AGA technical review on irritable bowel syndrome. Gastroenterology 2002;123:2108-31.

2 Madar Z, Thorne R. Dietary fiber. Prog Food Nutr Sci 1987;1 1:153-74.

3 Bliss DZ, Jung HJ, Savik K, et al. Supplementation with dietary fiber improves fecal incontinence. Nurs Res 2001;50:203-13.

4 Brodribb AJ. Treatment of symptomatic diverticular disease with a high-fibre diet. Lancet 1977;1:664-6.

5 Chandalia M, Garg A, Lutiohann D, et al. Beneficial effects of high dietary fiber intake in patients with type 2 diabetes mellitus. N Engl J Med 2000;342: 1392-8.

6 Marlett JA, McBurney MI, Slavin JL. Position of the American Dietetic Association: health implications of dietary fiber. J Am Diet Assoc 2002; 102:993-1000.

7 Hanson CF, Winterfeldt EA. Dietary fiber effects on passage rate and breath hydrogen. Am J Clin Nutr 1985;42:44-8.

8 Marthinsen $\mathbf{D}$, Fleming SE. Excretion of breath and flatus gases by humans consuming high-fiber diets. J Nutr 1982;112:1133-43.

9 Bond JH, Levitt MD. Effect of dietary fiber on intestinal gas production and small bowel transit time in man. Am J Clin Nutr 1978;31(suppl 10):S169-74.

10 Bergmann JF, Chassany $O$, Petit $A$, et al. Correlation between echographic gastric emptying and appetite: influence of psyllium. Gut 1992;33:1042-3.

11 Badiali D, Corazziari E, Habib Fl, et al. Effect of wheat bran in treatment of chronic nonorganic constipation. A double-blind controlled trial. Dig Dis Sci 1995;40:349-56.

12 Anderson $\mathrm{H}$, Bosaeus I, Falkheden T, et al. Transit time in constipated geriatric patients during treatment with a bulk laxative and bran: a comparison. Scand J Gastroenterol 1979;14:821-6.

13 Serra J, Azpiroz F, Malagelada JR. Intestinal gas dynamics and tolerance in humans. Gastroenterology 1998;115:542-50.

14 Lembo T, Naliboff B, Munakata J, et al. Symptoms and visceral perception in patients with pain-predominant irritable bowel syndrome. Am J Gastroenterol $1999 ; 94: 1320-6$

15 Francis CY, Whorwell PJ. Bran and irritable bowel syndrome: time for reappraisal. Lancet 1994;344:39-40.

16 Snook J, Shepherd HA. Bran supplementation in the treatment of irritable bowel syndrome. Aliment Pharmacol Ther 1994;8:51 1-14.

17 Bolin TD, Stanton RA. Flatus emission patterns and fibre intake. Eur J Surg Suppl 1998;582:115-18.

18 Tomlin J, Lowis C, Read NW. Investigation of normal flatus production in healthy volunteers. Gut 1991;32:665-9.

19 Levitt MD, Hirsh P, Fetzer CA, et al. $\mathrm{H}_{2}$ excretion after ingestion of complex carbohydrates. Gastroenterology 1987;92:383-9.

20 Wolever TM, Ter Wal P, Spadafora P, et al. Guar, but not psyllium, increases breath methane and serum acetate concentrations in human subjects. Am J Clin Nutr 1992;55:719-22.

21 Marteau P, Flourie B, Cherbut C, et al. Digestibility and bulking effect of ispaghula husks in healthy humans. Gut 1994;35:1747-52.

22 Levitt MD, Furne J, Olsson S. The relation of passage of gas and abdominal bloating to colonic gas production. Ann Intern Med 1996; 124:422-4.

23 Al-Khaldi SF, Martin SA, Prakash L. Fermentation of fenugreek fiber, psyllium husk, and wheat bran by Bacteroides ovatus V975. Curr Microbiol 1999;39:231-2. 
24 Kumar A, Kumar N, Vii JC et al. Optimum dosage of ispaghula husk in patients with irritable bowel syndrome: correlation of symptom relief with whole gut transit time and stool weight. Gut 1987;28:150-5.

25 Eastwood MA, Smith AN, Brydon WG, et al. Comparison of bran, isphagula, and lactulose on colon function in diverticular disease. Gut 1978:19:1144-7.

26 Ashraf W, Park F, Lof J, et al. Effects of psyllium therapy on stool characteristics, colon transit and anorectal function in chronic idiopathic constipation. Aliment Pharmacol Ther 1995:9:639-47.

27 Stevens J, VanSoest PJ, Robertson JB, et al. Comparison of the effects of psyllium and wheat bran on gastrointestinal transit time and stool characteristics. J Am Diet Assoc 1988;88:323-6.

28 Miller MA, Parkman HP, Urbain JL, et al. Comparison of scintigraphy and lactulose breath hydrogen test for assessment of orocecal transit. Lactulose accelerates small bowel transit. Dig Dis Sci 1997:42:10-18.

29 Sims MA, Hasler WL, Chey WD, et al. Hyperglycemia inhibits mechanoreceptor-mediated gastrocolonic responses and colonic peristaltic reflexes in healthy humans. Gastroenterology 1995:108:350-9.
30 Harder $\mathrm{H}$, Serra J, Azpiroz F, et al. Reflex control of intestinal gas dynamics and tolerance in humans. Am J Physiol Gastrointest Liver Physiol 2004;286:G89-94.

31 Hodgson WJ. An interim report on the production of colonic diverticula in the rabbit. Gut 1972;13:802-4.

32 Brodribb AJ, Condon RE, Cowles V, et al. Effect of dietary fiber on intraluminal pressure and myoelectrical activity of left colon in monkeys. Gastroenterology 1979;77:70-4.

33 Manning AP, Heaton KW, Harvey RF. Wheat fibre and irritable bowel syndrome. A controlled trial. Lancet 1977:2:417-18.

34 Findlay JM, Smith AN, Mitchell WD, et al. Effects of unprocessed bran on colon function in normal subjects and in diverticular disease. Lancet 1974;1:146-9.

35 Fioramonti J, Bueno L. Motor activity in the large intestine of the pig related to dietary fibre and retention time. $\mathrm{Br} J$ Nutr 1980:43:155-62.

36 Thorburn HA, Carter KB, Goldberg JA, et al. Does ispaghula husk stimulate the entire colon in diverticular disease? Gut 1992;33:352-6.

37 Lasser RB, Bond JH, Levitt MD. The role of intestinal gas in functional abdominal pain. N Engl J Med 1975;293:524-6.

\section{EDITOR'S QUIZ: GI SNAPSHOT}

\section{A phenomenal response to treatment by an advanced tumour}

Robin Spiller, Editor

\section{Clinical presentation}

A 44 year old woman presented with a longstanding history of epigastric pain, weight loss, and dysphagia. Upper gastrointestinal duodenoscopy demonstrated an $8 \mathrm{~cm}$ infiltrating tumour of the proximal $(40 \mathrm{~cm})$ stomach, and biopsy of the lesion demonstrated a necrotic solid tumour with a predominant epithelioid morphology arranged in small solid clusters with multiple scattered mitotic figures. Immunohistochemical staining revealed strong expression of vimentin, CD34, and c-kit in virtually all tumour cells. In view of her symptoms and histological findings, a contrast enhanced computed tomography (CT) scan of her abdomen was performed (fig 1).

\section{Question}

What do the investigations reveal as the likely diagnosis, and what are the treatment options for this patient?

See page 1616 for answer

This case is submitted by:

S H Rahman, A Roy, M Leahy, P J Guillou, G J Toogood St James's University Hospital, Leeds, UK

Correspondence to: Mr S H Rahman, St James's University Hospital, Beckett St, Leeds LS2 2LY, UK; zak-rahman@lineone.net

doi: 10.1136/gut.2003.029611

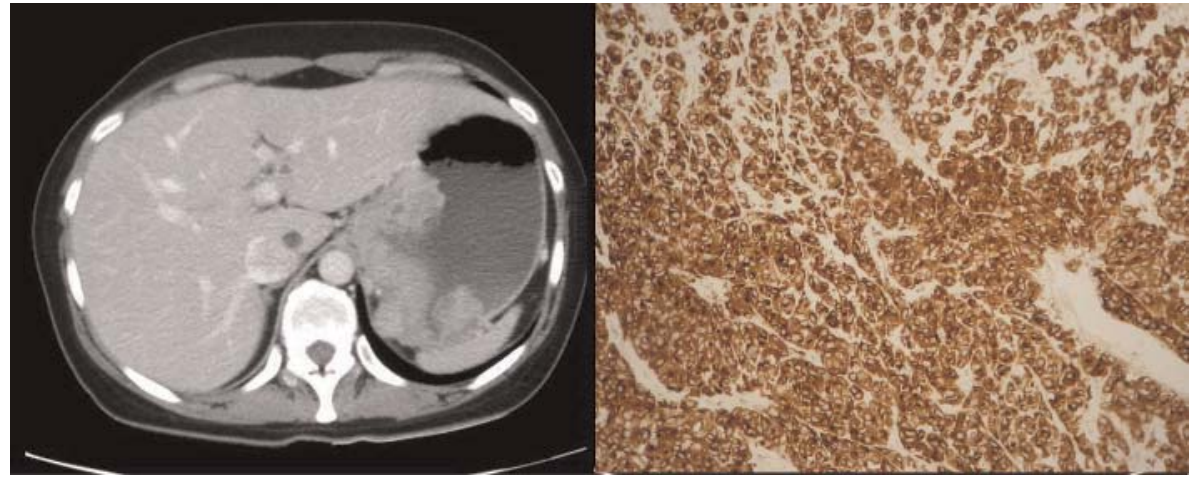

Figure 1 Contrast enhanced computed tomography scan of the abdomen (left) and immunohistochemical staining of the biopsy specimen of the lesion (right). 